\title{
Qualidade de serviços nas organizações do terceiro setor
}

\author{
Cristiano Rocha Heckert EPUSP \\ Márcia Terra da Silva EPUSP
}

\section{RESUMO}

Este artigo examina a qualidade de serviços nas organizações do terceiro setor. Por meio de revisão da literatura e de um estudo de caso, discutemse as diferenças na aplicação do conceito de qualidade de serviços (expectativas X percepção dos clientes) no terceiro setor em comparação com as empresas de mercado. Conclui-se que as organizações do terceiro setor não apresentam um único tipo de cliente, mas diversos stakeholders que assumem esse papel. Cada um desses atores possui diferentes expectativas com relação à instituição e apresenta diferentes critérios de avaliação da qualidade de seus serviços. Destaca-se, ainda, que, em função de valores como "justiça" e "solidariedade", fundamentais neste tipo de organização, o processo de prestação de serviços assume especial relevância no terceiro setor, sendo muitas vezes tão ou mais importante que os resultados obtidos.

\section{PALAVRAS-CHAVE}

Qualidade de serviços, organizações do terceiro setor, gestão de operações de serviços.

\section{Service quality in nonprofit organizations}

\begin{abstract}
This article analyses service quality in nonprofit organizations. Based on a literature review and a case study, it discusses the differences in applying the service quality concept (customer expectations $X$ perception) in the nonprofit sector, in comparison to for-profit companies. It concludes that nonprofits don't present a single type of customer, but several stakeholders playing that role. Each of those actors has different expectations towards the organization and presents different criteria when evaluating service quality. It should also be pointed that, due to values such as "justice" and "solidarity", essential in that type of organization, the service deliver process assumes special importance in nonprofits and, sometimes, become as or even more important than the results obtained.
\end{abstract}

\section{KEY WORDS}

Service quality, nonprofit organizations, service operations management. 


\section{INTRODUÇÃO}

As organizações da sociedade civil sem fins lucrativos têm tido participação cada vez maior na sociedade, tanto no Brasil quanto no exterior. Não sendo entidades públicas, nem tampouco empresas privadas orientadas para a lucratividade, as organizações beneficentes, religiosas, esportivas, culturais, entre outras, têm sido agrupadas sob a denominação "organizações do terceiro setor".

\section{s doadores oferecem dinheiro e tempo em troca de gratidão, reconhecimento ou satisfação de necessidades psicológicas.}

Somente nos Estados Unidos da América, segundo Drucker (1999), oitenta milhões de pessoas dedicam parte regular de seu tempo, todas as semanas, para trabalhar em alguma organização do terceiro setor. Enquanto o setor empresarial constituía $80 \%$ do PIB e o Estado era responsável por outros $14 \%$, o terceiro setor já representava, no início dos anos 1990, 6\% da economia nacional e envolvia 9\% da população ocupada naquele país (RIFKIN, 1995). No ano 2000, os ativos das organizações sem fins lucrativos norteamericanas alcançaram dois trilhões de dólares e sua receita anual ultrapassou setecentos bilhões de dólares (BRADLEY et al., 2003).

$\mathrm{Na}$ Inglaterra, o número de entidades cresceu $53 \%$ entre 1989 e 2004 (BENNETT \& BARKENSJO, 2005). No Brasil, segundo matéria publicada na Folha de S. Paulo (1999), um milhão e meio de pessoas trabalhavam, naquele ano, em organizações do terceiro setor e a taxa anual de crescimento dessa mão-de-obra era superior a dez por cento.

As organizações do terceiro setor também estão começando a perceber a importância de contarem com modelos e ferramentas de gestão mais eficientes. Segundo Brown e Kalegaonkar (2002), muitas iniciativas da sociedade civil surgem de empreendedores talentosos ou visionários, os quais têm pouca experiência em organizar e gerir organizações além do nível da coordenação informal. Enquanto operam em escalas pequenas, conseguem subsistir dessa forma. Porém, quando se tornam atores centrais em transformações sociais, políticas e econômicas importantes em larga escala, como ocorreu recentemente em muitos países, torna-se nítida sua carência de habilidades financeiras, gerenciais e organizacionais.

O crescimento do terceiro setor tem despertado diversos pesquisadores. Se até recentemente aquelas organizações eram estudadas, principalmente, nas Ciências Sociais e Políticas, nos últimos anos, pesquisadores de Administração, Economia e Engenharia de Produção passaram a se aproximar desse universo.

Contudo, ainda hoje, somente pequena parcela do conhecimento administrativo à disposição das instituições sem fins lucrativos foi concebida especificamente para elas. A maior parte foi desenvolvida originalmente para os setores público e empresarial (DRUCKER, 1999). Segundo Verma et al. (2005), ainda há a necessidade de se formar um corpo de teorias referentes à gestão de operações aplicável especificamente às organizações sem fins lucrativos.

Diversos autores conceituam terceiro setor. Um dos trabalhos mais citados tem sido o de Salamon e Anheier (1997), os quais, a partir de pesquisa realizada em 22 países, apresentam uma "definição estrutural-operacional", composta de cinco características que de alguma forma devem estar presentes em todas organizações do terceiro setor:

- Organizadas: ainda que não sejam legalmente formalizadas, precisam ter um sentido de permanência em suas atividades, possuir conselhos e realizar reuniões periódicas;

- Privadas;

- Não distribuidoras de lucros: ainda que as receitas sejam maiores que as despesas, todo o "lucro" deve ser revertido para a própria organização;

- Autogovernáveis: devem existir de forma independente do Estado ou de alguma empresa;

- Voluntárias: devem apresentar algum grau de voluntariado, tanto no trabalho quanto no financiamento (doações).

No Brasil, os primeiros trabalhos sobre administração de organizações do terceiro setor datam da virada dos anos 1990 para a presente década (FALCONER,1999; COELHO, 2000; HECKERT, 2001). Apesar do crescente número de estudos, trata-se de um campo ainda pouco explorado.

Falconer (1999) identifica quatro aspectos principais a serem desenvolvidos na gestão do terceiro setor (Tabela 1). Segundo o autor, cada um desses aspectos engloba uma série de ações e deve ser estudado em profundidade, constituindo uma agenda para a formação de um campo de conhecimento específico de administração de organizações sem fins lucrativos.

Dos quatro desafios colocados por Falconer (1999), a qualidade de serviços é a que está mais ligada à Engenharia de Produção. Tendo sido bastante estudada para organizações de mercado, sua aplicação no terceiro setor 
pode trazer grande contribuição para a melhoria da gestão nestas entidades.

Este artigo discute a qualidade de serviços nas organizações do terceiro setor. Por meio de revisão bibliográfica seguida de estudo de caso em uma organização real, procurase responder à seguinte questão: "em que aspectos o modelo organizacional do terceiro setor, caracterizado dentre outros fatores pela multiplicidade de públicos (stakeholders) que a organização precisa satisfazer, exige uma abordagem específica para o conceito de qualidade de serviços?”.

\section{REVISÃO BIBLIOGRÁFICA}

A Qualidade tem sido um tema bastante presente no campo de estudos da Engenharia de Produção. Originado no Japão nos anos 1950 e 1960, o movimento da Qualidade Total trouxe uma verdadeira revolução ao mundo empresarial. Nas últimas décadas, inúmeros autores desenvolveram pesquisas nessa área, gerando diversos conceitos, aplicados primeiramente na manufatura e, posteriormente, na área de serviços.

As particularidades dos serviços requerem uma abordagem própria para a Gestão da Qualidade. Diversos autores têm desenvolvido conceitos de Qualidade específicos para o setor de serviços. Zeithaml et al. (1990) propõem uma definição baseada na relação entre as expectativas do cliente antes da compra do serviço e a sua percepção durante e após sua prestação. Caso a percepção do cliente supere suas expectativas, o serviço será considerado de qualidade. Gianesi e Correa (1994) corroboram com essa definição, apresentando um modelo gráfico destacado na Figura 1.

O modelo de qualidade de serviços de Zeithaml et al. (1990), conhecido como SERVQUAL, tem sido largamente empregado em diversos países (KILBOURNE et al., 2004).
Seth et al. (2005), ao estudarem 19 diferentes abordagens para a qualidade de serviços destacam o papel central do SERVQUAL. Um grande número de trabalhos expande a proposta original de Zeithaml et al. (1990). Outros criticam-na. De qualquer forma, trata-se de uma referência básica para a grande maioria dos autores que abordam o tema.

A definição de qualidade proposta por Zeithaml et al. (1990) trabalha com o conceito de qualidade como "adequação ao uso", proposto por Juran (1988). A qualidade de um produto (ou serviço) será tão maior, quanto maior for a capacidade daquele produto (ou serviço) em satisfazer as necessidades (ou expectativas) do seu usuário.

Percebe-se que, em ambos os casos, a avaliação da qualidade depende muito mais dos valores atribuídos pelo cliente do que das características intrínsecas do produto ou serviço. Esses conceitos de qualidade, portanto, têm como referencial de avaliação o cliente (aquele que paga e recebe o serviço), e não o produto ou serviço fornecido.

Tal modelo se mostra bem adequado à lógica de operação das empresas de mercado. Nelas, a lucratividade e o crescimento da organização estão diretamente relacionados com a lealdade e a satisfação dos clientes, como mostram Heskett et al. (1997).

No terceiro setor, porém, não se verifica uma relação tão direta, pois o beneficiário, geralmente, não paga pelo serviço. Boa parte da receita das organizações do terceiro setor não provém de quem consome o serviço (beneficiário), mas de um terceiro elemento: o financiador. Para compreender essa distinção, é preciso analisar as diferenças existentes nas relações de troca no terceiro setor, em comparação com os outros tipos de organizações.

Segundo Kotler (1994), todas as organizações, sejam elas com ou sem fins lucrativos, se estabelecem e se mantêm através de relações de troca com seus vários mercados e públicos.

Tabela 1: Desafios de gestão para organizações do terceiro setor segundo Falconer (1999).

Desafio

Transparência'

Sustentabilidade

Qualidade de serviços

Capacidade de articulação
Descrição

Necessidade de transparência e responsabilidade da organização em prestar contas perante os diversos públicos que têm interesses legítimos diante delas.

Capacidade de captar recursos - financeiros, materiais e humanos - de maneira suficiente e continuada, e utilizá-los com competência, de maneira a perpetuar a organização e permiti-la alcançar os seus objetivos.

Uso eficiente dos recursos e avaliação adequada do que deve ser priorizado, em função dos recursos disponíveis, das necessidades do público e das alternativas existentes.

Formação de redes, fóruns, associações, federações e grupos de trabalho, de forma real ou virtual, permitindo articulação e intercâmbio de informação. 
Para que a troca se concretize, é necessário que ambas as partes se interessem pela relação, considerando que o benefício recebido compensa os valores e esforços despendidos.

Nas empresas de mercado, as relações de troca estão centradas, principalmente, em valores financeiros. Por um lado, os proprietários investem um capital na empresa, obtendo sua remuneração na forma de dividendos. Por outro lado, os clientes pagam à empresa pelo recebimento de bens e serviços cujo valor, em sua opinião, é igual ou superior ao montante despendido.

Nas organizações do terceiro setor, porém, aparecem outros valores não-financeiros nas relações de troca. Os doadores oferecem dinheiro e tempo em troca de gratidão, reconhecimento ou satisfação de necessidades psicológicas. Enquanto isso, os beneficiários recebem serviços sem oferecer uma contrapartida tangível à organização. $\mathrm{Na}$ verdade, o que oferecem é a possibilidade de a organização desempenhar sua missão, o que em última análise leva à satisfação de necessidades psicológicas de seus fundadores e membros.

Percebe-se, portanto, que a natureza das relações de troca é mais complexa e intangível no terceiro setor em comparação com as organizações de mercado. Fica claro também que, no terceiro setor, não existe relação direta entre satisfação dos beneficiários e sobrevivência da en- tidade. Como os recursos provêm dos financiadores, sua satisfação também é fundamental para a sobrevivência da instituição.

As organizações do terceiro setor não se relacionam com um público preferencial, como é o caso dos clientes nas empresas de mercado. Ao contrário, existem diversos públicos com diferentes expectativas. Como a organização busca (ou deve buscar) satisfazer a todos eles, todos poderiam, de certa forma, ser considerados "clientes". Entretanto, a preferência é pelo uso do termo stakeholders, definidos como os públicos interessados na organização (SZAZI, 2000). Segundo Kotler (1994), dois são os principais: beneficiários e financiadores. Entretanto, outros são também importantes como voluntários, governo e sociedade.

A multiplicidade de stakeholders-clientes com os quais as organizações do terceiro setor precisam lidar traz conseqüências sobre a avaliação da qualidade dos serviços. " $O$ feedback que as empresas recebem dos clientes (ou a falta dele) e que o setor público recebe das urnas é muito fraco no terceiro setor" (HUDSON, 1999, p.17). Isso não significa que a qualidade de serviços seja irrelevante no terceiro setor. Ao contrário, em um ambiente cada vez mais concorrido, ela é fator fundamental para a satisfação de beneficiários e financiadores e a conseqüente sobrevivência da organização.

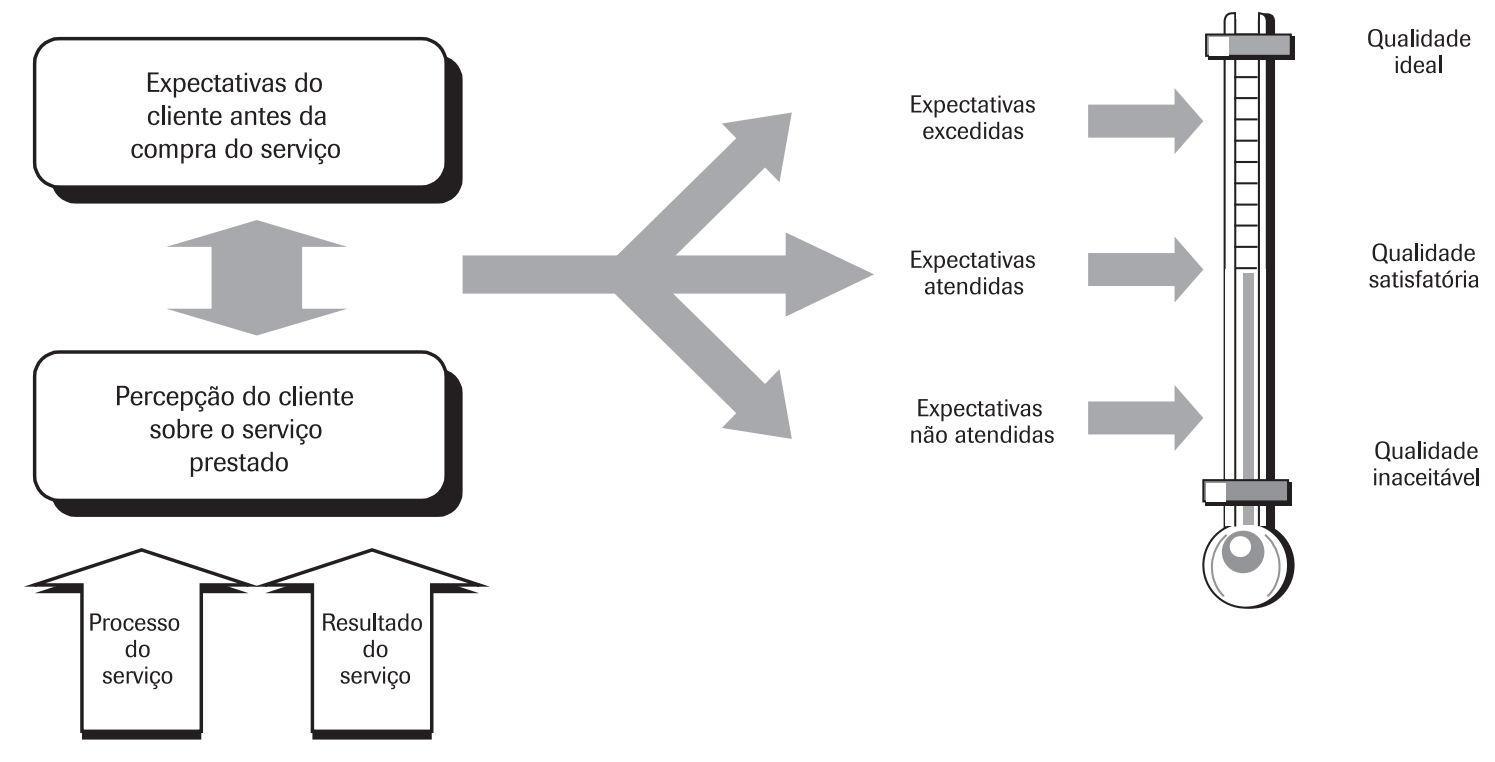

Figura 1: A avaliação da qualidade do serviço.

Fonte: Gianesi e Corrêa (1994). 
Não obstante, a aplicação do conceito de qualidade de serviços no terceiro setor deve levar em consideração as características próprias daquelas organizações. Nessa análise, é preciso observar três aspectos relevantes:

- Definir quem é o cliente;

- Identificar as expectativas e percepções do cliente;

- Definir o objeto de avaliação da qualidade.

Em primeiro lugar, é preciso definir quem é o cliente das organizações do terceiro setor. Segundo SMITH (1994), mais que qualquer outro setor, a filantropia traz consigo múltiplas razões e múltiplos clientes e a instituição precisa definir a melhor maneira de servir a cada um deles.

Diferentes stakeholders-clientes apresentam diferentes expectativas, percepções e avaliações da qualidade dos serviços nas organizações do terceiro setor (RITCHIE et al., 1999). Conforme colocam Te'eni e Young (2003), conhecer bem as expectativas de cada um de seus públicos é condição essencial para atendê-los de maneira satisfatória.

Segundo Zeithaml et al. (1990), quanto maior o preço de um serviço, maior é a expectativa formada pelo cliente com relação a sua qualidade. No caso de serviços gratuitos, portanto, a expectativa dos beneficiários tende a ser baixa. De fato, muitas vezes, os beneficiários vêem os serviços prestados pelas organizações do terceiro setor como ações de caridade e não se sentem no direito de reivindicar nada além do que lhes é oferecido. Predomina a idéia de que estão recebendo um favor e, por isso, devem se considerar satisfeitos (COELHO, 2000). Essa visão, muitas vezes, é alimentada pelas próprias organizações do terceiro setor, que desejam manter uma relação assistencialista / paternalista com os beneficiários. Diante disso, se a avaliação se basear apenas nas expectativas e percepções dos beneficiários, o serviço tende a ser sempre considerado de alta qualidade.

Como a satisfação dos beneficiários não se traduz diretamente em aumento da receita, o aumento da qualidade do serviço oferecido àqueles pode até, num primeiro momento, ter um impacto negativo para o caixa da organização, uma vez que pode levar ao aumento nos custos das operações sem uma contrapartida financeira imediata (HUDSON, 1999). Isso pode levar à falsa percepção de que é suficiente manter a qualidade dos serviços em um nível médio, sem se buscar a excelência.

Porém, segundo Bennet e Barkensjo (2005), algumas organizações do terceiro setor já convivem em um cenário de concorrência pelos beneficiários com outras instituições similares. A mudança do paradigma de suboferta para o de superoferta, ocorrida no mundo empresarial há três ou quatro décadas, começa a chegar também ao terceiro setor, constituindo-se em importante impulsionador para a melhoria da qualidade dos serviços.

Já os voluntários tendem a possuir expectativas bastante elevadas, pois esperam encontrar nas organizações do terceiro setor espaço para a satisfação de uma série de necessidades psicológicas, assim como a possibilidade de convivência e de participação em um grupo democrático. Da mesma forma, os financiadores esperam que a organização aplique bem os valores doados, garantindo a eles a satisfação de contribuírem com uma causa de valor. doadores oferecem dinheiro e tempo em troca de gratidão, reconhecimento ou fação de necessidades psicológicas.

As diferenças de expectativas e avaliação entre os diversos stakeholders-clientes trazem enorme potencial de conflito para a organização. Se, por um lado, sua missão está voltada ao atendimento das necessidades dos beneficiários, por outro, a necessidade de sobrevivência obriga-as a se voltarem para as expectativas dos financiadores. Ainda por um outro lado, a necessidade de receber subsídios ou um título concedido por um órgão público pode levar a organização a despender recursos significativos no atendimento dos requisitos da burocracia estatal. O grande risco é que, na ânsia de atender a públicos tão diversos, a organização acabe negligenciando o beneficiário e desvirtuando-se de sua missão.

A terceira particularidade da qualidade de serviços nas organizações do terceiro setor está no objeto da avaliação. Segundo Zarifian (2001), o conceito de serviço não pode ser reduzido a uma mudança física ou mental que traz benefícios a um destinatário, como tratado pela literatura tradicional. O serviço é, antes de tudo, uma produção de valor. E o valor não se esgota no consumo em si. Ele é tanto maior, quanto maior for a melhoria gerada nas condições de atividade de quem recebe o serviço.

Nas empresas de mercado, ainda que se considerem diferentes dimensões da qualidade, a avaliação tende a se concentrar no que Zarifian (2001) denomina "valor de utilidade" do serviço. Esse valor se refere à "adequação ao uso" de um serviço, transformando o estado do cliente ou sua capacidade para o exercício de determinada atividade. Entretanto, aquele autor expande o conceito de valor, estabelecendo que, em quaisquer serviços, além do valor de utilidade, devem também ser avaliados os seguintes valores: 
- Valor de justiça: igualdade de acesso aos serviços para todos. A justiça deve ser avaliada pela coletividade (através do Estado) e pelo destinatário do serviço;

- Valor de solidariedade: capacidade dos serviços de promover a integração social, a cooperação e a qualidade da vida coletiva;

- Valor de estética: misto de avaliação de beleza e de ética.
Parmar (2002) ressalta que qualquer metodologia de operação carrega consigo uma concepção ideológica sobre aquele serviço. Estudando o apoio dado por instituições norte-americanas a projetos desenvolvidos por organizações do terceiro setor na Ásia, na África e na América Latina, o autor mostra como, ao financiar determinados projetos, aquelas instituições reforçavam concepções mais alinhadas à sua ideologia. Esse componente não pode, portanto, ser desprezado, principalmente no terceiro setor, no qual a missão da organização representa papel tão preponderante.

Percebe-se que a aplicação dos conceitos de qualidade nas organizações do terceiro setor requer que se observe uma

Apesar dos valores de justiça, solidariedade e estética serem aplicáveis a quaisquer serviços, eles ganham especial relevância no terceiro setor. Segundo Tenório (1998), nesse setor, tão importante quanto o atendimento às necessidades dos beneficiários é a promoção da democracia e da cidadania. Nesse sentido, é importante que o processo de prestação dos serviços perca o caráter impessoal e incorpore mecanismos efetivos de participação, enriquecimento do trabalho e integração entre o prestador e o beneficiário.

Sowa et al. (2004) propõem uma abordagem multidimensional para a avaliação da efetividade nas organizações do terceiro setor. O método proposto considera duas dimensões:

- Efetividade de gestão: refere-se às características organizacionais e de gestão, ou seja, àquelas que descrevem a organização e a maneira como seus dirigentes agem dentro dela;

- Efetividade de programas: está relacionada com uma intervenção ou serviço específico oferecido pela organização.

Cada uma dessas dimensões é decomposta em dois subcomponentes: "capacidade" e "resultados". A avaliação da capacidade considera como a organização ou o programa é operado, as estruturas adotadas e os processos que dirigem as ações dos funcionários. Já os resultados são o produto das atividades de gestão e dos programas.

Conforme colocam Herman e Renz (1999), avaliar uma organização do terceiro setor simplesmente pelos resultados de seus programas é uma abordagem limitada e perigosa. Segundo os autores, os próprios stakeholders-clientes não se limitam a essa avaliação, mas consideram outros aspectos como, por exemplo, o respeito da organização a seus valores morais. série de aspectos próprios daquelas entidades. Com o intuito de verificar como são tratadas no cotidiano daquelas organizações as questões discutidas até aqui no plano teórico, foi realizado um estudo de caso, apresentado a seguir.

\section{ESTUDO DE CASO}

Segundo Voss et al. (2002), o estudo de caso é um dos mais poderosos métodos de pesquisa em gestão de operações. Sua utilização é recomendada em quatro situações: exploração de áreas ainda não suficientemente cobertas, construção de uma nova teoria, teste de uma teoria existente e extensão de uma teoria. Neste último caso, ele permite ver o quão generalizável é a teoria e em que contextos ela se aplica. Trata-se, portanto, de um método adequado ao presente trabalho, considerando que o estudo da gestão de operações no terceiro setor é recente e que esta pesquisa objetiva avaliar se uma teoria construída originalmente no mundo empresarial pode ser estendida ao terceiro setor.

Empreendeu-se um estudo de caso na Associação de Assistência à Criança Deficiente (AACD). Foram entrevistados dirigentes da organização (Gerente do Hospital, Gerente Financeiro, Gerente do Setor de Sócios-Contribuintes e Presidente do Voluntariado), assim como representantes de seus diversos stakeholders-clientes. Serviram também como fontes de dados: documentos da organização, seu sítio na Internet e a observação dos pesquisadores em diversas visitas realizadas à instituição.

A AACD foi criada em 1950, inspirada em centros de reabilitação semelhantes existentes nos Estados Unidos da América. Teve forte influência do sentimento dominante no pós-guerra de reconstrução e recuperação da dignidade humana, expresso na criação da Organização das Nações Unidas (ONU) e na Declaração Universal dos Direitos 
Humanos, com o slogan "all rights for all" (direitos iguais para todos).

A missão da AACD é "proporcionar atendimento, tratamento, educação e reabilitação às crianças e adolescentes portadores de alguma deficiência física". O artigo primeiro do seu Estatuto estabelece que: "A Associação de Assistência à Criança Defeituosa $a^{2}$, sociedade civil de intuitos não lucrativos e duração ilimitada, com sede e foro na cidade de São Paulo, tem por finalidade precípua instituir e coordenar um amplo serviço de assistência médica, pedagógica e social aos menores com defeitos físicos ortopédicos, visando, após a recuperação do defeito físico, o seu reajustamento social" (AACD, 2000).

Outros documentos consultados afirmam que uma das principais metas da instituição é possibilitar a integração do deficiente físico à sociedade, buscando sua independência financeira e profissional e visando dar à criança portadora de deficiências físicas, além do tratamento clínico ou cirúrgico, ampla assistência complementar, envolvendo treinamento físico, educacional, apoio e orientação vocacional.

A AACD é uma das maiores organizações do terceiro setor no Brasil, com orçamento próximo a cem milhões de reais. Sua matriz de arrecadação é bem diversificada, conforme apresentado na Tabela 2.

Os atendimentos realizados pela instituição em suas oito unidades têm crescido ano a ano, como mostra a Figura 2.

A AACD se classifica no que Hudson (1999) denomina "organização do terceiro setor prestadora de serviços". A variedade de suas fontes de recursos e de públicos com que interage a tornam representativa para o estudo da qualidade de serviços no terceiro setor aqui proposto.

Após obter a visão do prestador do serviço, expressa nas entrevistas com os profissionais e nos documentos da organização, procurou-se ouvir seus clientes. Tornou-se imprescindível, portanto, identificar os stakeholders que assumem o papel de clientes na AACD (chamados neste

Tabela 2: Receitas da AACD em 2006.

\begin{tabular}{cc}
\hline Fonte de receita & Milhares de R\$̧ \\
\hline Internações & 39.445 \\
Oficina ortopédica & 12.982 \\
Centro de reabilitação & 6.008 \\
Subvenções governamentais & 2.491 \\
Doações - Mantenedores & 3.816 \\
Doações - Teleton & 14.264 \\
Doações - Outros & 4.058 \\
Venda de cartões de Natal & 8.400 \\
Rendimento de aplicações financeiras & 1.326 \\
Receitas não operacionais & 160 \\
Receitas diversas & 2.430 \\
\hline Total & 95.380
\end{tabular}

Fonte: AACD (2006)

\section{AACD - Número de atendimentos por ano}

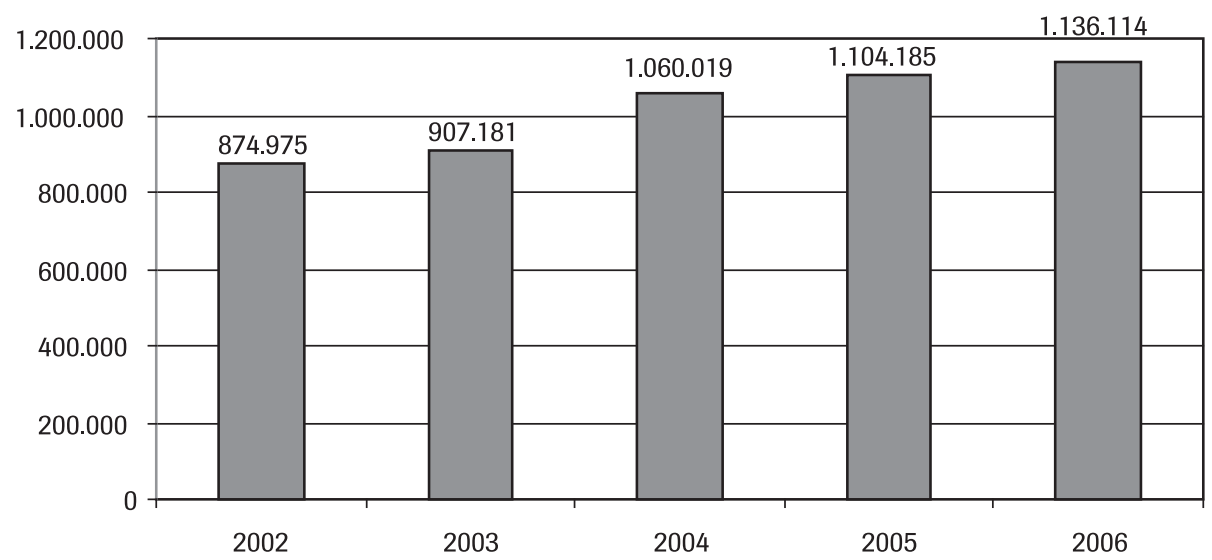

Figura 2: Número de atendimentos por ano na AACD.

Fonte: AACD (2006). 
trabalho de stakeholders-clientes). Após análise conjunta dos pesquisadores e de dirigentes da organização estudada, eles foram agrupados em cinco segmentos: beneficiários, familiares de beneficiários, sócios-contribuintes, voluntários e profissionais autônomos.

Para a realização das entrevistas com os stakeholdersclientes, foi utilizada a abordagem dos "incidentes críticos" de Hayes (1992). Esse autor propõe um método estruturado para se avaliar a satisfação dos clientes de uma organização, baseado em apenas uma pergunta: "Cite 5 a 10 exemplos positivos e 5 a 10 exemplos negativos que lhe chamaram a atenção em sua relação com a organização".

Nessa etapa e a partir desse método, foram realizadas vinte e uma entrevistas com os stakeholders-clientes que resultaram na identificação de 149 incidentes críticos (Tabela 3).

Levantados os incidentes críticos, seguiu-se sua análise

Tabela 3: Número de entrevistas e de incidentes críticos.

\begin{tabular}{ccc}
\hline Stakeholder-cliente & Entrevistas & Incidentes críticos \\
\hline Beneficiários & 4 & 28 \\
Familiares & 4 & 30 \\
Voluntários & 5 & 62 \\
Sócios-contribuintes & 5 & 11 \\
Profissionais autônomos & 3 & 18 \\
\hline Total & 21 & 149
\end{tabular}

Elaborada pelos autores conforme dados de pesquisa realizada em 2001. e agrupamento. Segundo Hayes (1992), incidentes críticos devem ser categorizados em itens de satisfação, que em seguida são agrupados em dimensões da qualidade (Figura 3). Incidentes positivos e negativos podem ser incluídos em um mesmo item de satisfação. Por exemplo, os incidentes "esperei muito para ser atendido" e "fui atendido prontamente" referem-se ao mesmo item de satisfação: "tempo de espera para ser atendido".

Após análise criteriosa de todos os incidentes críticos, buscando as melhores categorias de agrupamento, chegou-se a uma estrutura com 16 itens de satisfação e sete dimensões da qualidade (Tabela 4). Nesse agrupamento, foram utilizadas como referência as dimensões da qualidade propostas por Zeithalm et al. (1990), com as alterações sugeridas por Gianesi e Corrêa (1994).

A análise dos incidentes críticos levantados pelos stakeholders-clientes mostra que os aspectos mais valorizados em cada segmento não são necessariamente os mesmos. Enquanto alguns itens de satisfação e dimensões da qualidade são comuns a diferentes públicos, outros são específicos a um ou dois deles. Essas diferenças são decorrentes dos distintos motivos que levam cada grupo a procurar a AACD, estabelecendo com ela diferentes relações de troca.

Os beneficiários e familiares procuram a instituição para a realização de um tratamento. Como se constatou nas entrevistas realizadas, a maioria vem à instituição sob indicação de um médico ou de outro profissional de saúde. Assim, não questionam a competência dos profissionais da AACD,

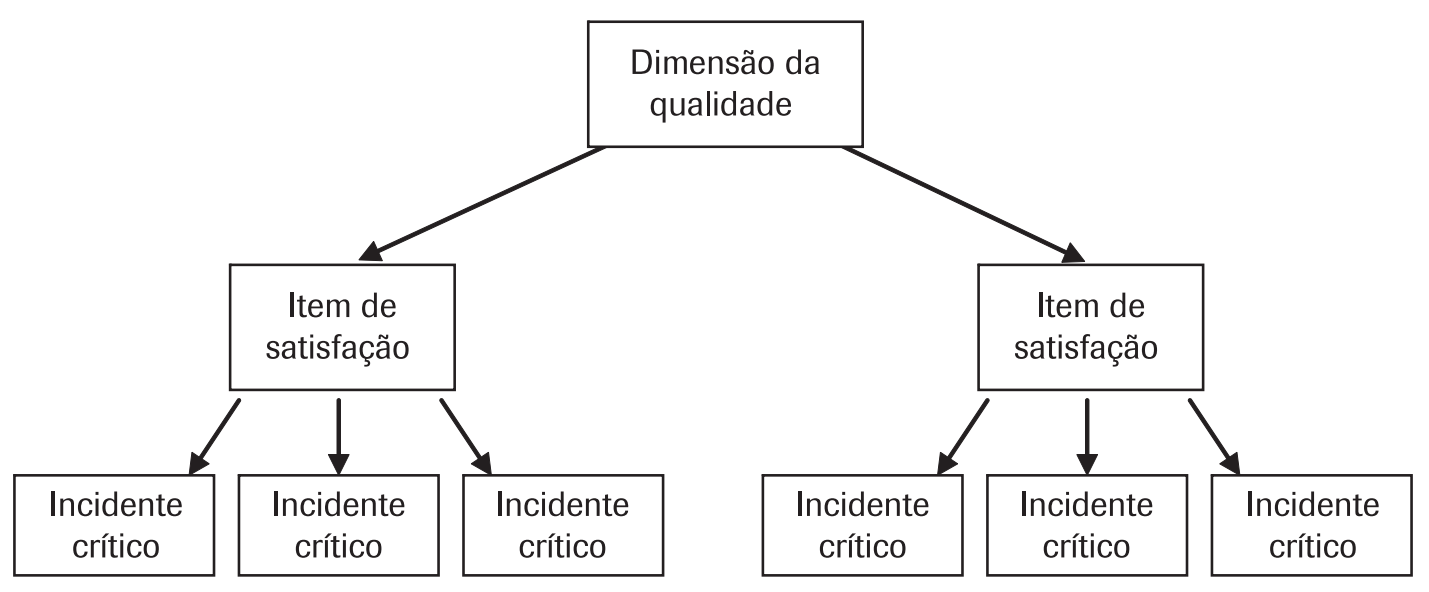

Figura 3: Hierarquia de relacionamentos: incidentes críticos, itens de satisfação, dimensões da qualidade. Fonte: Hayes (1992). 
pois confiam na indicação dos profissionais especializados.

Preocupam-se mais com aspectos ligados ao atendimento, como responsividade e acesso.

Por outro lado, um dos itens mais relevantes para os profissionais autônomos é a competência da equipe de apoio. Eles optam por realizar uma cirurgia na AACD e não em outro hospital por acreditarem que lá seus pacientes terão um melhor acompanhamento pré e pós-operatório. Pesam também na escolha, a qualidade e a disponibilidade dos recursos para o bom desempenho de seu trabalho.

Já os sócios-contribuintes e os voluntários esperam receber de uma instituição do terceiro setor gratidão, reconhecimento e satisfação de necessidades psicológicas. Assim, os principais motivos apontados para procurarem a AACD foram reconhecer a importância de sua missão e sua efetividade em cumpri-la.

A Tabela 5 apresenta uma síntese das dimensões da qualidade mais valorizadas por cada um dos cinco grupos de stakeholders-clientes considerados na pesquisa.

\section{COMENTÁRIOS FINAIS}

As observações realizadas na pesquisa de campo confirmam o que fora levantado na literatura, permitindo concluir que as organizações do terceiro setor se distinguem das empresas de mercado na abordagem do conceito de qualidade de serviços em três aspectos.

\section{Tão importante quanto 0 atendimento às necessidades dos beneficiários é a promoção da democracia e da cidadania.}

Em primeiro lugar, foi constatada a presença de múltiplos stakeholders na condição de clientes. Ao contrário das empresas, que possuem um cliente com perfil mais delimitado, as organizações de terceiro setor lidam com uma variedade maior de públicos desempenhando tal papel. Diante disso, a abordagem da qualidade de serviços no terceiro setor deve se iniciar pela identificação dos diversos stakeholders-clientes da organização.

Em segundo lugar, observou-se que os diferentes stakeholders-clientes não apresentam expectativas e necessidades homogêneas. Ao contrário, cada grupo prioriza um determinado conjunto de dimensões da qualidade, de acordo com os motivos e expectativas que os levam a procurar a organização. Expectativas diferentes levam a diferentes critérios de avaliação da qualidade e diferentes graus de exigências, demonstrando que determinados stakeholders-

Tabela 4: Dimensões da qualidade e itens de satisfação na AACD.

\begin{tabular}{cc}
\hline Dimensões da qualidade & Itens de satisfação \\
\hline Acesso & Acessibilidade \\
Competência & Competência dos profissionais \\
& Relacionamento e sincronismo na equipe de \\
trabalho & História e crescimento \\
Credibilidade & Causa de valor \\
& Transparência nas ações \\
Efetividade & Desenvolvimento das capacidades das pessoas \\
& Resultados visíveis \\
Preço & Auto-sustentabilidade \\
& Gratuidade do serviço \\
Responsividade & Cortesia no atendimento \\
& Atendimento ágil e na hora marcada \\
& Desejo de oferecer o melhor serviço \\
Qualidade dos equipamentos & Adequãão e limpeza das instalações \\
& Disponibilidade de recursos
\end{tabular}

Elaborada pelos autores. 
clientes são mais rigorosos do que outros na apreciação dos serviços.

Se, por um lado, os requisitos são distintos entre os diversos grupos de stakeholders-clientes, por outro, observou-se, dentro de um mesmo segmento, bastante homogeneidade nas dimensões mais destacadas. Essa singularidade demonstra coerência de posicionamento entre os elementos de cada grupo, sendo que, pelo que se pôde concluir da pesquisa realizada, o principal fator condicionante dos requisitos dos clientes são as relações de troca que estabelecem com a organização.

da na qualidade de serviços no terceiro setor. Nas empresas de mercado, num raciocínio bastante simplificado 3 , melhorar a qualidade dos serviços implica em atrair mais clientes, aumentando a lucratividade do empreendimento. No terceiro setor, porém, como a maioria dos serviços é gratuita ou subsidiada, ao atrair mais clientes, a organização, ao invés de aumentar sua receita, aumenta seus custos.

Assim, mesmo considerando os ganhos obtidos com a maior eficiência operacional alcançada, a qualidade de serviços no terceiro setor nunca pode ser abordada sem examinar seus impactos no fluxo de caixa da organização. Em um país no qual as condições sociais precárias da maior parte da população configuram uma demanda quase ilimitada para os serviços prestados pelas organizações do terceiro setor, esforços para a melhoria da qualidade

O terceiro aspecto observado é o destaque maior conferido aos valores de justiça e solidariedade, em detrimento do valor de utilidade dos serviços. Isso se deve à natureza dos serviços nas organizações do terceiro setor, nas quais o processo de prestação engloba fatores como a promoção da cidadania, da solidariedade e da democracia. Assim, não é possível avaliar a qualidade exclusivamente em função dos resultados alcançados. Ênfase especial deve ser dada aos processos de prestação dos serviços, verificando se a maneira como são conduzidos contempla os valores de justiça e solidariedade.

Por fim, vale destacar uma aparente contradição observa- de serviços e aumento no número de beneficiários atendidos devem ser sempre acompanhados de um aumento nas fontes de captação de recursos. Caso contrário, a organização corre o risco de, na busca por atender a todos os necessitados, comprometer sua sempre frágil sustentabilidade financeira, colocando em risco sua sobrevivência a médio prazo.

Em outras palavras, o conceito de qualidade de serviços no terceiro setor deve conjugar duas definições de qualidade, baseadas no usuário e no valor, apontadas por Garvin (1988): qualidade é satisfazer as necessidades dos consumidores a um preço aceitável.

Tabela 5: Síntese das dimensões da qualidade mais valorizadas por cada grupo de stakeholders-clientes.

\begin{tabular}{cc}
\hline Stakeholders-clientes & Dimensões da qualidade mais valorizadas \\
\hline Beneficiários & Responsividade, preço e acesso \\
Familiares & Responsividade, acesso e recursos tangíveis \\
Voluntários & Efetividade, competência, credibilidade e responsividade \\
Sócios-contribuintes & Credibilidade \\
Profissionais autônomos & Competência e recursos tangíveis \\
\hline Elaborada pelos autores. &
\end{tabular}

Elaborada pelos autores.

Artigo recebido em 31/01/2006

Aprovado para publicação em 26/03/2008 


\section{NOTAS}

1. FALCONER (1999) utiliza o termo em sua versão original em inglês (accountability).

2. Inicialmente denominada Associação de Assistência à Criança Defeituosa, a AACD teve posteriormente seu nome alterado para Associação de Assistência à Criança Deficiente.

3. Sabe-se que, na realidade, a qualidade é hoje nas empresas muito mais um "fator qualifica- dor" do que um "fator ganhador de pedidos". Assim, não necessariamente melhorar a qualidade leva a um aumento na lucratividade, mas é sim uma condição obrigatória à sobrevivência da organização.

\section{REFERÊNCIAS}

AACD. Vida é movimento. São Paulo: AACD, 2000.

Relatório de atividades 2006. São Paulo: AACD, 2006.

BENNETT, R.; BARKENSJO, A. Relationship quality, relationship marketing, and client perceptions of the levels of service quality of charitable organizations. International Journal of Service Industry Management, v. 16, n. 1, p. 81-106, 2005.

BRADLEY, B.; JANSEN, P.; SILVERMAN, L. The nonprofit sector's $\$ 100$ billion opportunity. Harvard Business Review, p. 94-103, May 2003.

BROWN, L. D.; KALEGAONKAR, A. Support Organizations and the Evolution of the NGO Sector. Nonprofit and Voluntary Sector Quarterly, v. 31, n. 2, p. 231-258, 2002.

COELHO, S. C. T. Terceiro setor: um estudo comparado entre Brasil e Estados Unidos. São Paulo: Editora Senac, 2000.

DRUCKER, P. F. Administração de Organizações sem fins lucrativos: princípios e Práticas. 5a edição, São Paulo: Pioneira, 1999.

FALCONER, A. P. A promessa do terceiro setor. um estudo sobre a construção do papel das organizações sem fins lucrativos e do seu campo de gestão. Dissertação de Mestrado, Universidade de São Paulo, São Paulo, 1999.

FOLHA DE S. PAULO. Caderno especial Folha Trainee - "Profissão: solidário", 18 de setembro de 1999.
GARVIN, D. What quality product realy means?. Harvard Business Review, May-June 1988.

GIANESI, I. N.; CORRÊA, H. L. Administração estratégica de serviços: operações para satisfação do cliente. São Paulo: Atlas, 1994.

HAYES, B. E. Measuring customer satisfaction: development and use of questionnaires. Milwaukee: ASQC Quality Press, 1992.

HECKERT, C. R. Qualidade de serviços em organizações do terceiro setor. Dissertação (Mestrado). São Paulo: Universidade de São Paulo, 2001.

HECKERT, C. R.; SILVA, M. T. Qualidade de Serviços nas Organizações do Terceiro Setor. Anais. XXI Encontro Nacional de Engenharia de Produção. Salvador, 2001.

HERMAN, R. D.; RENZ, D. O. Theses on Nonprofit Organizational Effectiveness. Nonprofit and Voluntary Sector Quarterly, v. 28, n. 2, p. 107-126, 1999.

HESKETT, J.; SASSER, W. E.; SCHELINGER, L.A. The service profit chain: How Leading Companies Link Profit and Growth to Loyalty, Satisfaction, and Value. New York: The Free Press, 1997.

HUDSON, M. Administrando organizações do terceiro setor. o desafio de administrar sem receita. Tradução de James F. Sunderland Cook. São Paulo: Makron Books, 1999.

JURAN, J. Quality Control Handbook. New York: McGraw-Hill, 1988.
KILBOURNE, W. E.; DUFFY, J. A. A.; DUFFY, M.; GIARCHI, T. The applicability of SERVQUAL in cross-national measurements of health care quality. Journal of Services Marketing, v. 18, n. 7, p. 524-533, 2004

KOTLER, P. Marketing para organizações que não visam lucro. Tradução de $\mathrm{H}$. de Barros. 4. ed. São Paulo: Atlas, 1994.

PARMAR, I. American foundations and the development of international knowledge networks. Global Networks, v. 2, n. 1, p. 13-30, 2002.

RIFKIN, J. O fim dos empregos: o declínio inevitável dos níveis dos empregos e a redução da força global de trabalho. Tradução de Ruth Gabriela Bahr. São Paulo: Makron Books, 1995.

RITCHIE, R. J. B; SWAMI, S.; WEINBERG, C. B. A brand new world for nonprofits. International Journal of Nonprofit and Voluntary Sector Marketing, v. 4, n. 1, p. 26-42, 1999.

SALAMON, L. M.; ANHEIER, H. K. Defining the nonprofit sector. Baltimore: John Hopkins University Press, 1997.

SETH, N.; DESHMUKH, S. G.; VRAT, P. Service quality models: a review. International Journal of Quality and Reliability Management, v. 22, n. 9, p. 913-949, 2005.

SMITH, C. The New Corporate Philantropy. Harvard Business Review, p. 105-116, MayJune 1994 
SOWA, J. E.; SELDEN, S. C.; COLLEGE, L. No Longer Unmeasurable? A Multidimensional Integrated Model of Nonprofit Organizational Effectiveness. Nonprofit and Voluntary Sector Quarterly, v. 33, n. 4, p. 711-728, 2004.

SZAZI, E. Terceiro Setor: Regulação no Brasil. São Paulo: Peirópolis, 2000.

TE'ENI, D.; YOUNG, D. R. The Changing Role of Nonprofits in the Network Economy. Nonprofit and Voluntary Sector Quarterly, v. 32, n. 3, p. 397-414, 2003
TENÓRIO, F. G. Gestão social: metodologia e casos. Rio de Janeiro: Editora da Fundação Getúlio Vargas, 1998.

VERMA, R.; McLAUGHLIN, C.; JOHNSTON, R.; YOUNGDAHL, W. Operations management in not-for-profit, public and government services: Charting a new research frontier. Journal of Operations Management, v. 23, p. 117-123, 2005

VOSS, C.; TSIKRIKTSIS, N.; FROHLICH, $\mathrm{M}$. Case research in operations manage- ment. International Journal of Operations \& Production Management, v. 22, n. 2, p. 195219, 2002.

ZARIFIAN, P. Valor, organização e competência na produção de serviço In: SALERNO, M. (Org.) Relação de serviço: produção e avaliação. São Paulo: Editora SENAC, 2001.

ZEITHAML,V. A.; PARASURAMAN,A.; BERRY, L. L. Delivering Quality Service. New York: The Free Press, 1990.

\section{SOBRE OS AUTORES}

\section{Cristiano Rocha Heckert}

Departamento de Engenharia de Produção

Escola Politécnica da Universidade de São Paulo (POLI-USP)

End.: SQN 208 Bloco G Apto. 206 - Asa Norte - Brasília - DF - CEP 70853-070

Tel.: res. (61) 3253-7155 cel.: (61) 9273-0266

E-mail: heckert@usp.br

\section{Márcia Terra da Silva}

Departamento de Engenharia de Produção

Escola Politécnica da Universidade de São Paulo (POLI-USP)

End.: Av. Prof. Almeida Prado, Travessa 2, no 128 - Cidade Universitária - São Paulo - SP - CEP 05508-900

Tel. com.: (11) 3091-5363

E-mail:mtdsilva@usp.br 